\title{
Treatment of chronic vulvovaginal candidiasis with posaconazole and ciclopiroxolamine
}

\section{Hans-Jürgen Tietz}

Fungal Infection and Microbiology Institute, Berlin, Germany; tietz@institut-fuer-pilzkrankheiten.de

Received 21 January 2010; revised 30 January 2010; accepted 2 February 2010.

\begin{abstract}
Therapy of chronic recurrent vulvovaginal candidiasis (VVC) caused by Candida glabrata is still rare in comparison to $C$. albicans infection, but therapy remains more difficult. Combination therapy with topical antifungals may improve therapy outcome, but still standard agents as fluconazole or itraconazole often fail. Posaconazole is a new systemic triazole with a wide antifungal spectrum including rare Candida species. Up to now, no clinical trials with posaconazole in chronic recurrent VVC have been undertaken. Here, first results of the application of a new therapy regimen consisting of oral posaconazole in combination with topical ciclopiroxolamine are presented. 15 patients with chronic recurrent VVC caused by C. glabrata have been treated. 14 of these patients experienced successful therapy, clinical and mycological cure $\mathbf{3 0}$ days after begin of therapy has been observed. Long-term results are promising, as in 4 patients clinical and mycologic cure persists for more than 1 year up to now.
\end{abstract}

Keywords: Chronic Recurrent Vulvovaginal Candidiasis; VVC; Candida Glabrata; Posaconazole

\section{INTRODUCTION}

Vulvovaginal candidiasis (VVC) is termed chronic if it recurs four times or more per year at intervals of 8 weeks or less [1]. Literature data suggest that acute vulvovaginal candidiasis becomes chronic in 5-8 \% of cases $[2,3]$. Possible, but heatedly debated, risk factors for vaginal thrush include prior antibiotic or corticosteroid therapy, intrauterine contraceptive devices (coil), highsugar diet, and certain sexual practices [2]. The etiology of chronic recurrent VVC is little understood even today. Gastrointestinal tract as a reservoir for re-infection, re-infection from sexual partner(s), and recurrent disease as a result of persistent colonization have been postulated. This last postulate is supported by studies showing recurrent disease to be caused by identical strains in the vast majority of cases [2].

Though C. albicans is the main pathogen in more than $95 \%$ of cases of acute infection [4], other species are implicated in chronic infection, chiefly C. glabrata. The characteristic features of Candida albicans and Candida glabrata are listed in Table $\mathbf{1}$.

The pathogenic role of C. glabrata is disputed, but patients who present to a physician with fungal disease caused by these atypical pathogens always report symptoms. Though vaginal discharge is rare, redness, agonizing itching, and a sour-smelling sticky discharge are characteristic. A diagnosis of "harmless commensal" is therefore both inappropriate and scientifically inaccurate. Both organisms are biosafety class 1 organisms. Hence, though low-virulence, they are not apathogenic - unlike Saccharomyces cerevisiae.

\section{TREATMENT OF PROBLEM FUNGI}

The therapeutic goal in chronic recurrent VVC is the eradication of the pathogen. The chances of achieving that goal appear to be good. Unlike C. albicans, nonalbicans Candida organisms are located predominantly vaginally. Measures to prevent recurrence should be initiated before starting therapy [5]. Oral and bowel contamination in the patient ( 3 fecal samples taken on 3 different days) should be investigated, which may result in measures such as professional dental and denture cleaning and eradication of pathogens in the mouth and bowel with amphotericin B or nystatin (C. glabrata) in the form of lozenges or sugar-coated tablets. A hormonal coil is a potential pathogen reservoir and should ideally be removed before therapy. The sexual partner should be involved in treatment too. Colonization of the prostate (sperm sample) and contamination of dentures (smear tests) in older partners should be investigated. 
Table 1. Characteristics of C. albicans and C. glabrata as organisms causing vaginal candidiasis.

\begin{tabular}{|c|c|c|}
\hline Property & C. albicans & C. glabrata \\
\hline Etiology & Mostly intra partum & Frequently iatrogenic \\
\hline Course & Acute & Chronic \\
\hline Findings & $\begin{array}{l}\text { Discharge } \\
\text { Redness } \\
\text { Pruritus }\end{array}$ & $\begin{array}{l}\text { Redness } \\
\text { Pruritus }\end{array}$ \\
\hline Virulence class & 2 (high) & 1 (low) \\
\hline Pseudomycelium & Yes & No \\
\hline Blastospores & midsize, oval & Small-cell, round \\
\hline Chlamydospores & Yes & No \\
\hline Hormone situation & Dependent & No \\
\hline Antifungal & \multicolumn{2}{|c|}{$\begin{array}{l}\text { Pathogen susceptibility }(\mathrm{S}=\text { sensitive, } \mathrm{R}=\text { re- } \\
\text { sistant })\end{array}$} \\
\hline Clotrimazole & $\mathrm{S}$ & $\mathrm{R}$ \\
\hline Nystatin & S & S \\
\hline Ciclopiroxolamine & $\mathrm{S}$ & S \\
\hline Fluconazole & $\mathrm{S}$ & $\mathrm{R}$ \\
\hline Posaconazole & S & S \\
\hline $\begin{array}{l}\text { Drug of first choice: } \\
\text { - topical } \\
\text { - systemic }\end{array}$ & $\begin{array}{l}\text { Clotrimazole } \\
\text { Fluconazole }\end{array}$ & $\begin{array}{l}\text { Ciclopiroxolamine } \\
\text { Posaconazole }\end{array}$ \\
\hline
\end{tabular}

Drug therapy should encompass both a topical and a systemic component. C. glabrata is located deep in vaginal tissue-up to 10 layers deep-which explains the high failure rate for local treatment attempts. C. glabrata also thrives in surface locations-under the foreskin, around the clitoris, in the anal folds and pubic hair-and so the effectiveness of systemic therapy is limited. Therefore, combination therapy seems to be necessary to appropriately treat the patient and avoid recurrence of infection. It needs to be stressed that in addition, patient cooperation is crucial, as rigorous, reliable local treatment is required in conjunction with properly administered systemic therapy.

C. glabrata isolates have very low sensitivity to fluconazole and may be resistant in many cases. Secondary resistance is mainly due to two factors: genetic variability of the pathogen, which develops resistance to fluconazole at doses below $800 \mathrm{mg}$, and the fact that many therapists administer fluconazole doses as low as $150 \mathrm{mg}$ [6]. In contrast, in vitro sensitivity to posaconazole is high [7]. Until just a few years ago, systemic high-dose treatment with $800 \mathrm{mg}$ fluconazole was the treatment of first choice [8]. Given the large number of current treat- ment failures, the treatment approach is not advisable today [5]. Nevertheless, the options for treating invasive fungal infection of the kind are better now than ever. The most promising agents according to the current state of scientific knowledge are the triazole derivative posaconazole and the echinocandins caspofungin and anidulafungin. The latter require intravenous dosing and are associated with high treatment costs. Since vaginal candidiasis is usually treated in an ambulatory setting, these agents are of lesser relevance for treatment.

Ciclopiroxolamine is the most effective local drug for treating clotrimazole- and nystatin-resistant organisms [8]. It is the antifungal with the broadest spectrum, as well as showing deep penetration and sporicidal activity. The mechanism of action is polyvalent. Ciclopiroxolamine's activity is not limited to the level of ergosterol synthesis. It also targets regions mitochondria and protein synthesis, making it the ideal combination partner for all systemic antifungals. Inhibition of catalase production is particularly effective, because it disables metabolization of toxic $\mathrm{H}_{2} \mathrm{O}_{2}$ occurring in the fungal cell. All clinically relevant Candida species are sensitive to ciclopiroxolamine [8].

Posaconazole is a triazole derivative whose mechanism of action is based on inhibiting ergosterol synthesis [9]. It is effective against a variety of fungal pathogens. These include all relevant Aspergillus species, the organisms responsible for mycetoma, coccidioidomycosis, chromoblastomycosis, and refractory pathogens like Mucor and Fusarium [10,11]. The spectrum of action also includes Candida and especially the problem pathogens C. glabrata and C. krusei $[7,10]$ which are resistant to fluconazole, itraconazole and voriconazole. Posaconazole's molecular structure gives it multiple docking sites, so different mutations would have to occur simultaneously for it to be ineffective [12]. In contrast, a single mutation is enough to induce resistance to fluconazole [12]. Posaconazole has linear kinetics up to a dose of $800 \mathrm{mg}$ [9]. Exposure can be increased by division into two divided doses of $400 \mathrm{mg}(10 \mathrm{ml}$ suspension BID), and is further enhanced by dosing together with high-fat food, e.g. custard made with full-fat milk. It has a high volume of distribution (1744 liters), suggesting very good distribution. Posaconazole is metabolized to a very slight extent and is primarily eliminated with the feces. Posaconazole has the lowest potential for interactions of all systemic azole derivatives, since interactions with the CYP system are limited to CYP3A4 inhibition. The most common side effects reported in studies involving a total of 2400 subjects and patients were headache and nausea [9]. Posaconazole is approved for prevention of systemic infection in high-risk hemato-oncology patients, for salvage therapy of certain 
invasive mould infections and for the treatment of oropharyngeal candidiasis [9]. Up to now, there is no clinical data supporting efficacy in treatment of vaginal candidiasis. In a murine vaginal model, posaconazole reduced the fungal burden of both fluconazole-susceptible and fluconazole-resistant Candida albicans strains [4].

The difficulty to treat chronic vaginal infections caused by C. glabrata lead to the development of a concept comprising a posaconazole-ciclopiroxolamine combination therapy for patients, who seemed to have exhausted all conventional treatment options.

\section{PATIENTS}

Patients were eligible if they had a chronic vaginal candidiasis caused by C. glabrata, a history of therapy failure and reduced sensitivity towards licensed antifungals indicated by susceptibility testing.

All patients were carefully examined, including microbiologic and dermatologic diagnosis, to exclude nonfungal infections and a non-infectious dermatosis such as lichen ruber, neurodermitis or psoriasis inversa. To avoid recurrence, the patients' surroundings were carefully examined mycologically by taking swabs or samples and cultivation on appropriate media (see Diagnostic Procedures). This included the partner's oral cavity, penis and sperm, but also the patient's oral cavity, vagina, clitoris and faeces. Vaginal swabs of all patients were taken and cultured before start of therapy for species identification and susceptibility testing. Foreign objects as Nuva-Ring or hormonal coil were removed before start of therapy.

Therapy response was assessed by clinical and mycologic examination at 7 and 30 days after end of therapy, respectively. For some patients, long-term results up to 2 years after therapy are available. Patients who have been treated here come from all over Germany, so that long-term follow-up is not possible in every case. For mycologic examination, vaginal and clitoris swabs were taken and inoculated as described below. Further followup visits are conducted regularly, about every 30 days, the results are presented below.

A successful therapy outcome was defined as substantial improvement of the patient's clinical infection signs and symptoms 7 days after start of treatment, as well as persistent clinical and mycologic cure 30 days after begin of therapy.

All patients were informed about the compassionate use project in depth and about the existing database on posaconazole in antifungal treatment. Health insurance reimbursement was checked and agreed in advance for all patients.

\section{DIAGNOSTIC PROCEDURES}

For species identification, swabs were inoculated onto chromID ${ }^{\mathrm{TM}}$ Candida agar, bioMérieux Deutschland $\mathrm{GmbH}$, Nürtingen, Germany, which is specific for yeast isolation and direct identification of Candida albicans. Candida albicans colonies are coloured blue by specific hydrolysis of a hexosaminidase chromogenic substrate after 2 day of incubation at $37^{\circ} \mathrm{C}$. The species identification of non-blue-coloured colonies like C. glabrata and C. krusei were examined by their assimilation pattern with the ID 32C yeast identification system, bioMérieux Deutschland GmbH, Nürtingen, Germany. ID 32C system consists of a single-use disposable plastic strip with 32 wells to perform 29 assimilation tests (carbohydrates, organic acids, and amino acids), 1 assimilation test with a negative control, 1 susceptibility test (cycloheximide), and 1 colorimetric test (esculin) including a database of 63 different species. Results were recorded by direct reading after $48 \mathrm{~h}$ of incubation at $30^{\circ} \mathrm{C}$.

The susceptibility of all isolates towards itraconazole and flucoanzole was tested routinely, as these are the only systemic antifungal agents licensed to treat VVC. FUNGITEST $^{\mathrm{TM}}$, Bio-Rad, Marnes-la Coquette, France was used. In general, this test is used to study growth of yeasts in the presence of 6 antifungal agents at 2 different concentrations, among them fluconazole and itraconazole. Growth assessment is based on reduction of the coloured indicator which turns the medium from blue to pink. When growth is inhibited by the fungal agent, the medium remains blue. Two growth and 2 negative controls are included in the test system. The interpretation of the results was performed according the following colour characteristics: Blue-blue = no growth, strain inhibited by the antifungal agent, sensitive strain ("S"); Pink-blue = low growth, intermediate strain ("I"); Pinkpink $=$ growth, strain not inhibited by the antifungal agent, resistant strain ("R"). The breakpoints have been chosen following the study of the distribution of the antifungal agents MIC obtained with prototype microplates used with the same procedure as FUNGITEST ${ }^{\mathrm{TM}}$. If susceptibility testing indicates intermediate susceptibility or resistance towards fluconazole or itraconazole, therapy attempts with these agents cannot expect to be successful because of the genetic haploidy of $\mathrm{C}$. glabrata.

\section{THERAPY}

All patients received a combination of systemic and topical therapy (Table 1). For systemic therapy, posaconazole was administered for 15 days at a daily dose of $800 \mathrm{mg}$ (10 ml BID). Topical therapy consisted of ciclopiroxolamine cream BID administered intravaginally 
every morning and evening. 12 of the patients received additional topical treatment with Nystatin Ovula (100,000 IU q.d.). Further measures were initiated in addition, if required: shaving of pubic hair of both partners before initiating therapy; antifungal decontamination of both partners (mouth, bowel, sperm).

\section{RESULTS}

15 patients with chronic vaginal candidiasis caused by $\mathrm{C}$. glabrata were treated (Table 3). On average, they were 46.2 years old (range 20-76 years). For all patients, vaginal control swabs at baseline were positive for Candida glabrata, and most of the patients also had evidence of C. glabrata below the clitoral hood. 13 of the 15 patients had a history of failed treatment with fluconazole, 2 of these patients received even more than one systemic antifungal. Remaining 2 of the 15 patients had both been pretreated topically with clotrimazole. Both patients were infected with C. glabrata-strains that showed only intermediate susceptibility to fluconazole and itraconazole.

In total, 7 of $15 \mathrm{C}$. glabrata strains were resistant to fluconazole, 6 showed intermediate susceptibility and 2 results indicated susceptibility, although both patients experienced clinical failure with fluconazole. All 7 strains resistant towards fluconazole were also itraconazole-resistant, and in addition, one of the strains exhibiting intermediate susceptibility towards fluconazole tested itraconazole-resistant. No strain was itraconazolesusceptible.

All patients received treatment with posaconazole and ciclopiroxolamine in accordance with the regimen in Table 2. 14 of the 15 patients were treated successfully with this regimen: they experienced substantial clinical improvement already after 7 days of treatment; no clinical signs and symptoms of the infection could be dete- cted 30 days after begin of therapy, and all mycologic swabs were negative for Candida glabrata. 11 of the 14 patients with successful therapy outcome after 30 days could be monitored for a longer time to detect a possible recurrence of infection. No patient showed any sign or symptom of recurrent fungal infection, and culture diagnostics have always been negative since. Clinical and mycological cure persists for about 60 days in 4 patients, for 90 days in 3 patients and for more than 1 year in 4 of the patients. Clinical success of the applied therapy regimen is documented photographically. One patient (patient No. 7 in Table 3) experienced therapy failure. This patient evidently failed to implement the treatment processes. She was transferred to hospital for intravenous treatment with an echinocandin, and topical therapy has been stopped there. The patient experienced recurrence of infection. Posaconazole was well tolerated by all patients, similarly to fluconazole.

\section{DISCUSSIONS}

Modern systemic antifungals such as posaconazole open up prospects for successful and sustainable therapy. No clinical data are available to date on posaconazole in the treatment of chronic recurrent vaginal candidiasis. Preclinical data suggest that posaconazole may be an option for this difficult-to-treat infection [4,7,12]. Posaconazole activity against Candida species seems to be high [7].

The key to a successful cure seems to be the combination of the highly active substances posaconazole and ciclopiroxolamine. Since nystatin is effective against C. glabrata, it may be included in the treatment regimen as well.

Posaconazole has been favoured as systemic combination partner over an echinocandin, although the main indication of echinocandins is the therapy of Candida

Table 2. Regimen for treatment of refractory chronic vaginal fungal disease caused by C. glabrata (according to Tietz).

\begin{tabular}{|c|c|}
\hline Treatment & Conduct \\
\hline Oral & $\begin{array}{l}\text { Posaconazole, } 800 \mathrm{mg} \text { (suspension in } 3105-\mathrm{ml} \text { bottles) } \\
400 \mathrm{mg} \text { BID }=10 \mathrm{ml} \text { BID with high-fat food (e.g. custard made with full-fat milk) }\end{array}$ \\
\hline Local $^{1}$ : & Ciclopiroxolamine Cream $35 \mathrm{~g}$ \\
\hline A) morning & Introduce deep into the vagina and apply to labia, vaginal opening, under the foreskin/clitoral hood, and from perineum to anus \\
\hline B) evening & $\begin{array}{l}\text { Ciclopiroxolamine Cream } \mathbf{3 5} \mathbf{g} \text { (repeat as stated under A) } \\
\text { Additionally at night: } \\
\text { Nystatin Ovula, inserted at depth once daily }\end{array}$ \\
\hline Supportive & $\begin{array}{l}\text { A) Pubic shaving of both partners before starting therapy } \\
\text { B) Mouth, bowel and sperm of both partners must be fungus-free } \\
\text { C) Remove IUD beforehand }\end{array}$ \\
\hline
\end{tabular}

\footnotetext{
${ }^{1}$ Treatment takes place from treatment day 1 in parallel with systemic therapy. Patients are required to use up their full supply of drugs.
} 
Table 3. Therapy of chronic recurrent VVC in 15 patients with posaconazole and ciclopiroxolamine*.

\begin{tabular}{|c|c|c|c|c|c|c|c|c|c|c|c|}
\hline \multirow{3}{*}{ No } & \multirow{3}{*}{ Age } & \multicolumn{2}{|c|}{ Premedication } & \multicolumn{6}{|c|}{ Suceptibility testing } & \multirow{3}{*}{$\begin{array}{l}\text { Last negative } \\
\text { culture result after }\end{array}$} & \multirow{3}{*}{$\begin{array}{c}\text { Clinical and } \\
\text { myclogical cure }\end{array}$} \\
\hline & & \multirow{2}{*}{ Antimycotic } & \multirow{2}{*}{ Daily dosage } & \multicolumn{3}{|c|}{ Itraconazole } & \multicolumn{3}{|c|}{ Fluconazole } & & \\
\hline & & & & $\mathrm{S}$ & I & $\mathrm{R}$ & $\mathrm{S}$ & $\mathrm{I}$ & $\mathrm{R}$ & & \\
\hline 1 & 43 & Fluconazol & $800 \mathrm{mg}, 2$ weeks & & & $\mathrm{X}$ & & & $\mathrm{X}$ & 39 days & + \\
\hline 2 & 76 & $\begin{array}{l}\text { Fluconazol } \\
\text { Voriconazol } \\
\text { Anidulafungin } \\
\text { Caspofungin }\end{array}$ & $\begin{array}{c}400 \mathrm{mg}, 10 \text { days } \\
400 \mathrm{mg}, 6 \text { days } \\
50 \mathrm{mg}, 21 \text { days } \\
100 \mathrm{mg}, 10 \text { days } \\
50 \mathrm{mg}, 14 \text { days }\end{array}$ & & & $\mathrm{X}$ & & & $\mathrm{X}$ & 2 years & + \\
\hline 3 & 45 & Fluconazol & $800 \mathrm{mg}, 2$ weeks & & & $\mathrm{X}$ & & & $\mathrm{X}$ & 1 year & + \\
\hline 4 & 24 & Clotrimazol & several times & & $\mathrm{X}$ & & & $\mathrm{X}$ & & 92 days & + \\
\hline 5 & 20 & Fluconazol & $150 \mathrm{mg}$, once & & $\mathrm{X}$ & & $\mathrm{X}$ & & & 2 years & + \\
\hline 6 & 52 & $\begin{array}{l}\text { Fluconazol } \\
\text { Itraconazol }\end{array}$ & $\begin{array}{l}150 \mathrm{mg} \text {, once } \\
400 \mathrm{mg} \text {, once }\end{array}$ & & $\mathrm{X}$ & & $\mathrm{X}$ & & & 98 days & + \\
\hline 7 & 72 & Clotrimazol & Several times & & $\mathrm{X}$ & & & $\mathrm{X}$ & & non & non \\
\hline 8 & 51 & Fluconazol & $800 \mathrm{mg}, 2$ weeks & & $\mathrm{X}$ & & & $\mathrm{X}$ & & 56 days & + \\
\hline 9 & 44 & Fluconazol & $800 \mathrm{mg}, 2$ weeks & & & $\mathrm{X}$ & & & $\mathrm{X}$ & 90 days & + \\
\hline 10 & 63 & Fluconazol & $400 \mathrm{mg}, 2$ weeks & & & $\mathrm{X}$ & & $\mathrm{X}$ & & 1 year & + \\
\hline 11 & 34 & Fluconazol & $400 \mathrm{mg}, 2$ weeks & & $\mathrm{X}$ & & & $\mathrm{X}$ & & 60 days & + \\
\hline 12 & 51 & Fluconazol & $800 \mathrm{mg}, 2$ weeks & & & $\mathrm{X}$ & & & $\mathrm{X}$ & 60 days & + \\
\hline 13 & 30 & Fluconazol & $800 \mathrm{mg}, 2$ weeks & & & $\mathrm{X}$ & & & $X$ & 35 days & + \\
\hline 14 & 52 & Fluconazol & $150 \mathrm{mg}$, once & & $\mathrm{X}$ & & & $\mathrm{X}$ & & 76 days & + \\
\hline 15 & 37 & Fluconazol & $800 \mathrm{mg}, 2$ weeks & & & $\mathrm{X}$ & & & $\mathrm{X}$ & 35 days & + \\
\hline
\end{tabular}

* Patients had a history of treatment with $800 \mathrm{mg}$ over a 2-week period

infections. Echinocandins are only available in intravenous formulation, hence their application is complicated and maybe too costly in an ambulatory setting.

On the basis of the current state of scientific knowledge, it was possible to develop a treatment concept for successful treatment of patients who had exhausted conventional treatment options. From an ethical point of view, too, it was appropriate not to withhold the drug until marketing authorization. Unlike C. albicans fungal disease, which typically is associated with a high risk of re-infection, disease caused by C. glabrata was successfully cured. 14 of 15 patients in this drug use evaluation achieved a cure. The follow-up period ranged from 90 days to 2 years in 11 of the 14 patients, no relapses occurred. Concomitant topical treatment deserves merit as the second mainstay of success; systemic antifungals on their own will probably not reach all the remote niches in which pathogens may be present.

Larger clinical trials should be conducted to further study the efficacy of posaconazole in the treatment of chronic recurrent vaginal candidiasis caused by rare Candida species as C. glabrata and C. krusei.

\section{REFERENCES}

[1] Mendling, W. (2006) Vaginose, vaginitis, zervizitis und salpingitis. 2nd Edition, Springer Medizin Verlag, Heidelberg.

[2] Watson, C. and Calabretto, H. (2007) Comprehensive review of conventional and non-conventional methods of management of recurrent vulvovaginal candidiasis. Aust N Z J Obstet Gynaecol, 47(4), 262-272.

[3] Eschenbach, D.A. (2004) Chronic vulvovaginal candidiasis. New England Journal of Medicine, 351(9), 851-852.

[4] González, G.M., et al. (2007) Therapeutic efficacy of posaconazole against isolates of Candida albicans with different susceptibilities to fluconazole in a vaginal model. Medical Mycology, 45 (3), 221-224.

[5] Mendling, W., et al. (2008) Vulvovaginalkandidose. Guideline of the German Society of Gynecology and Ob- 
stetrics, German Dermatologic Society, German-Speaking Mycologic Society, Berlin.

[6] Czaika, V., et al. (2000) Antifungal susceptibility testing in chronically recurrent vaginal candidosis as basis for effective therapy. Mycoses, 43(Suppl 2), 45-50.

[7] Pfaller, M.A., et al. (2001) Vitro activities of posaconazole (Sch 56592) compared with those of itraconazole and Fluconazole against 3,685 clinical isolates of Candida spp. and Cryptococcus neoformans. Antimicrobial Agents and Chemotherapy, 45(10), 2862-2864.

[8] Tietz, H.J. and Sterry W. (2006) Antimykotika von A-Z., Thieme, 4.Auflage, Stuttgart.

[9] Smith, W.J., Drew, R.H. and Perfect, J.R. (2009) Posaconazole's impact on prophylaxis and treatment of inva- sive fungal infections: an update. Expert Review of AntiInfective Therapy, 7(2), 165-181.

[10] Herbrecht, R. (2004) Posaconazole: A potent, extended spectrum triazole antifungal for the treatment of serious fungal infections. International Journal of Clinical Practice, 58(6), 612-624.

[11] Schiller, D.S. and Fung, H.B. (2007) Posaconazole: An extended spectrum triazole antifungal agent. Clinical Therapeutics, 29(9), 1862-1886.

[12] Hof, H. (2008) Is there a serious risk of resistance development to azoles among fungi due to the widespread use and long-term application of azole antifungals in medicine? Drug Resistance Updates, 11(1-2), 25-31. 